\title{
Use of hybrid renewable energy systems for small communities
}

\author{
Georgeta Bandoc ${ }^{1, *}$, Ana-Maria Smaranda Florescu², Mircea Degeratu², and Remus Pravalie ${ }^{1}$ \\ ${ }^{1}$ University of Bucharest, Center for Coastal Research and Environmental Protection, Meteorology and Hydrology Department, \\ 1 Nicolae Balcescu Blvd., District 1, 010041 Bucharest, Romania \\ 2 Technical University of Civil Engineering Bucharest, Hydraulics and Environmental Protection Department, 124 Lacul Tei \\ Blvd., District 2, 020396 Bucharest, Romania
}

\begin{abstract}
The purpose of this article is to present how the sizing of a hybrid renewable energy system is done for a community of three hundred and five households located in a Delta, starting from the optimization of hybrid energy system for a single household. The methodology used in solving this problem is based on multiple options. The first option consists in determined energy needs, maximum power consumption in cold season and in adapting the solution for the production of electricity by a hybrid plant. The second option consists of energy needs resulted in average consumption of electricity in warm season and in adapting the solution for the production of electricity from a hybrid plant. In conjunction with the demand for electricity for the entire community one will get energy demand by aggregating household level (kWh/household). The novelty of this approach lies in the method used by these hybrid systems for obtaining electricity in small communities, isolated from this case study. Based on the results obtained the method can be expanded the implementation of these projects that use hybrid renewable energy systems.
\end{abstract}

\section{Introduction}

Given the current environmental challenges and growing of human society is facing, renewable energy will play a major role in global energy consumption [1]. Global climate changes such as increasing greenhouse effect, stratospheric ozone depletion, etc., generated by the development mentioned by IPCC which reports sounded the alarm for reducing carbon emissions, preventing the disruption of natural ecosystems. IPCC dramatically stated that the most important challenge for security of the society is climate warming [2-5]. In this context, the XXI century energy challenge is related to a transition towards a sustainable energy system. This system is based on three concepts: affordability, acceptability and availability. In other words, this sustainable energy system is characterized by unrestricted access to energy services, provides an effective supply of renewable, sustainable energy and, not least is a low carbon sources [6]. A valuable alternative energy generation from renewable sources is the development of decentralized energy production technologies. These solutions have a renewable energy source. They are hybrid systems which are the combination of two or more renewable energy solar, wind, biomass, etc., that satisfy the energy needs for micro-regions or isolated communities. To develop such projects, regional planning is important both for managing financial resources and how land use [7]. For the security of supply with renewable energy of a micro-

\footnotetext{
* e-mail: bandoc@geo.unibuc.ro
}

regions, isolated communities or urban space is needed to develop a working methodology that combines the power of different sources of renewable energy. Thus, according to Chauhan and Saini [8] the stages are: analysis of sustainable energy transitions, appraisal of decision factors, driving forces of the decision factors and scenarios building and development. Currently, there are a number of international projects such as Small Island Developing States Network, Energy Development in Island Nations, ECOWAS for Renewable Energy and Energy Efficiency (ECREEE), European Environment Island Net - work on Energy and Green Islands Project that have the purpose of implementing such hybrid power systems for small communities [9]. For the period 2010-2030, more than half of global investment budget will be made available for offgrids and mini isolated-grids [8].

\section{Methodology}

This paper proposes a case study regarding how to solve the energy demand for a small community, isolated, located in Danube Delta, based on the design and use of a hybrid energy system. Also, this study could form a model for analyzing the demand and consumption of energy for a small community starting from the needs of householders. For the success of such a project, besides financial and predicting of energy demand it requires an accurate assessment of renewable energy potential. The present study it is devoted to solar and wind potential assessment for a small village is Sfântu Gheorghe in the Danube 


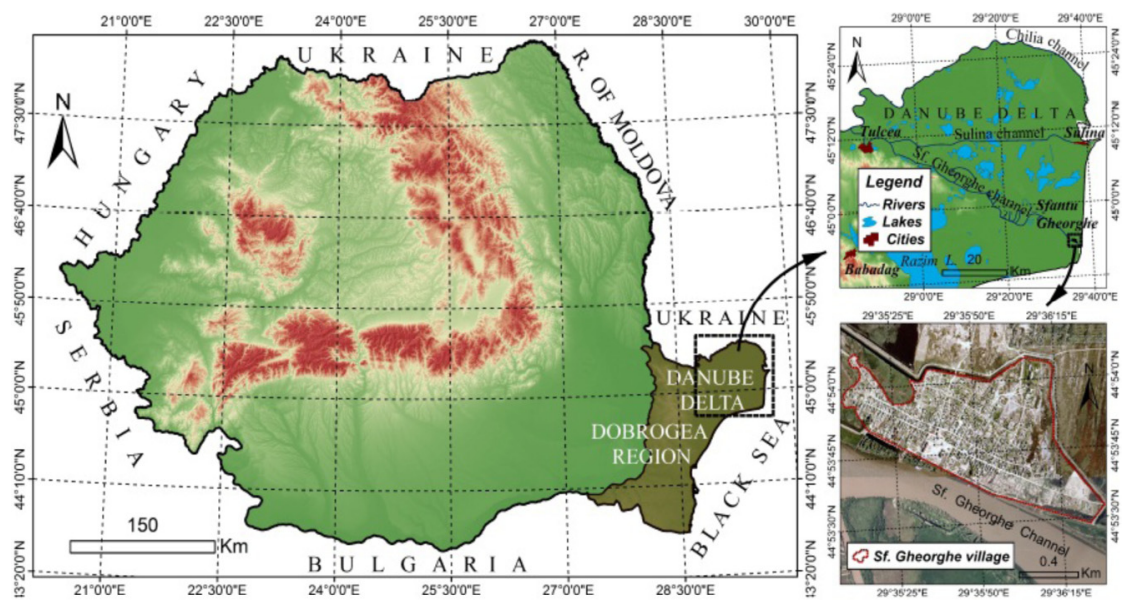

Fig. 1. Location of study area: Sfântu Gheorghe, Delta Dunării.

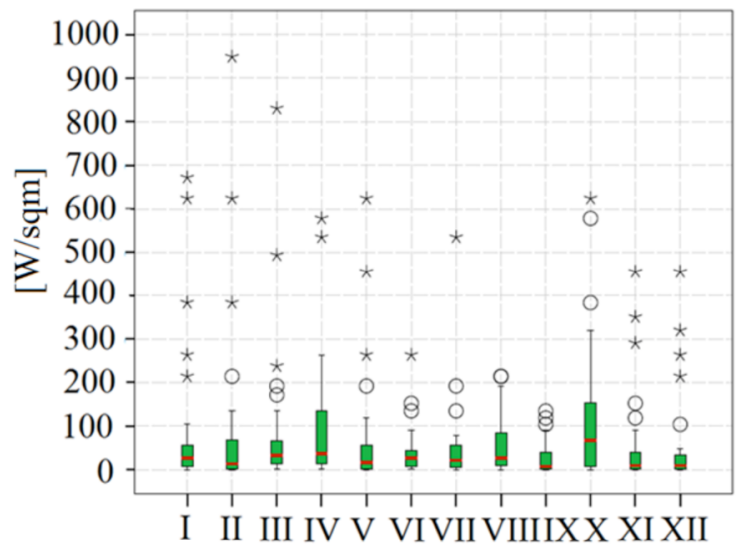

a)

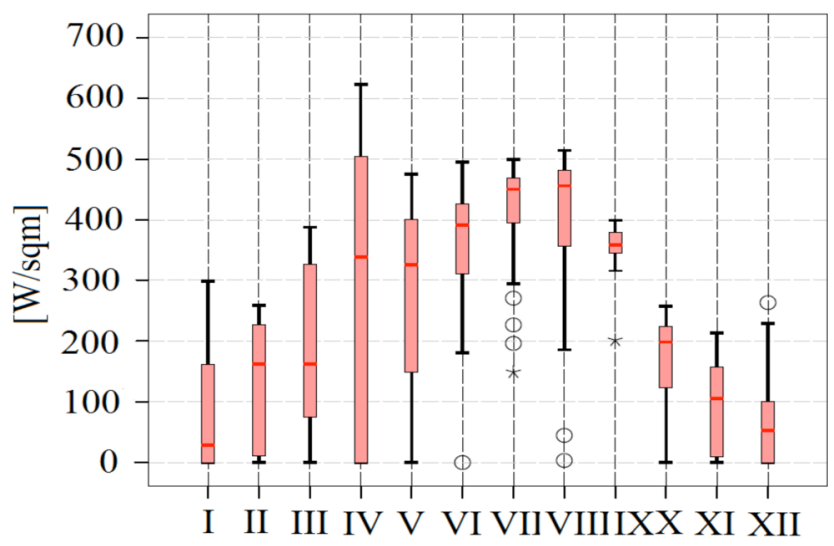

b)

Fig. 2. Characteristics energy potential at Sfântu Gheorghe: (a) wind, (b) solar.

Delta [10,11]. This community of Sfântu Gheorghe Delta has a population of 870 residents, a total of 672 homes and 350 households. The main economic activity is linked to fishing, tourism and navigation, primary and tertiary sector activities. For this community, the demand for electricity is the residential sector, other fields not representative balance of power. Located in the northwestern part of the Black Sea basin, wide area between $44^{\circ} 46^{\prime} 00^{\prime \prime} \mathrm{N}, 45^{\circ} 40^{\prime} 00^{\prime \prime}$ wide $28^{\circ} 40^{\prime} 24^{\prime \prime} \mathrm{N}$ and $29^{\circ} 40^{\prime} 50^{\prime \prime}$ long. E, as shown in Figure 1.

Implementation of a hybrid power generation network in a small community requires a series of detailed data related to wind regime, duration of sunshine and data related to energy resource potential that for the chosen space (wind, solar) (Fig. 2) [10,12]. Solar potential is good $2300 \mathrm{~h} /$ year of sunshine duration, average temperature $11^{\circ} \mathrm{C}$ temperature in January $1{ }^{\circ} \mathrm{C}, 22{ }^{\circ} \mathrm{C}$ temperature in July, the average wind speed of $4.6 \mathrm{~m} / \mathrm{s}$, calm atmosphere $<10 \%$. For a comprehensive analysis in terms of climatic characteristics it can be used remote sensing and GIS technologies.

For the community chosen must be known the amplitude of seasonal energy needs for a correct design of the hybrid system. It also requires knowledge of the growth rate from one season to another, so that the hybrid system designed to cope with increasing demand depending on needs. In estimating the maximum annual energy demand, are taken into account tourism activity which involves designing a system to cope with seasonal demands.

Also, a statistical study related to the wind regime based on Weibull probability distribution and Wind Power Density (WPD) was established in Class 2 wind potential in accordance with the scale of the US Department of Energy (DOE). Evaluation of reliability and robustness especially hybrid system is made based on certain factors. The first factor is related to the knowledge of hourly energy demand, weekly, monthly and annual activities based on energy usage description of economic activities, the overall rate of economic growth, number of inhabitants, population growth rate, number of households, the production facility, the existence of a resort, a hotel, etc. The second factor is the technical details of the hybrid system: supply of daily and monthly technical details about the production and storage, etc.

For this study was chosen a home study that is built on the parcel of land with the function of housing, the house has ground floor and one floor. The building occupies a ground area of about 170 square meters and has a built surface of about 290 square meters. The residence, which has been 


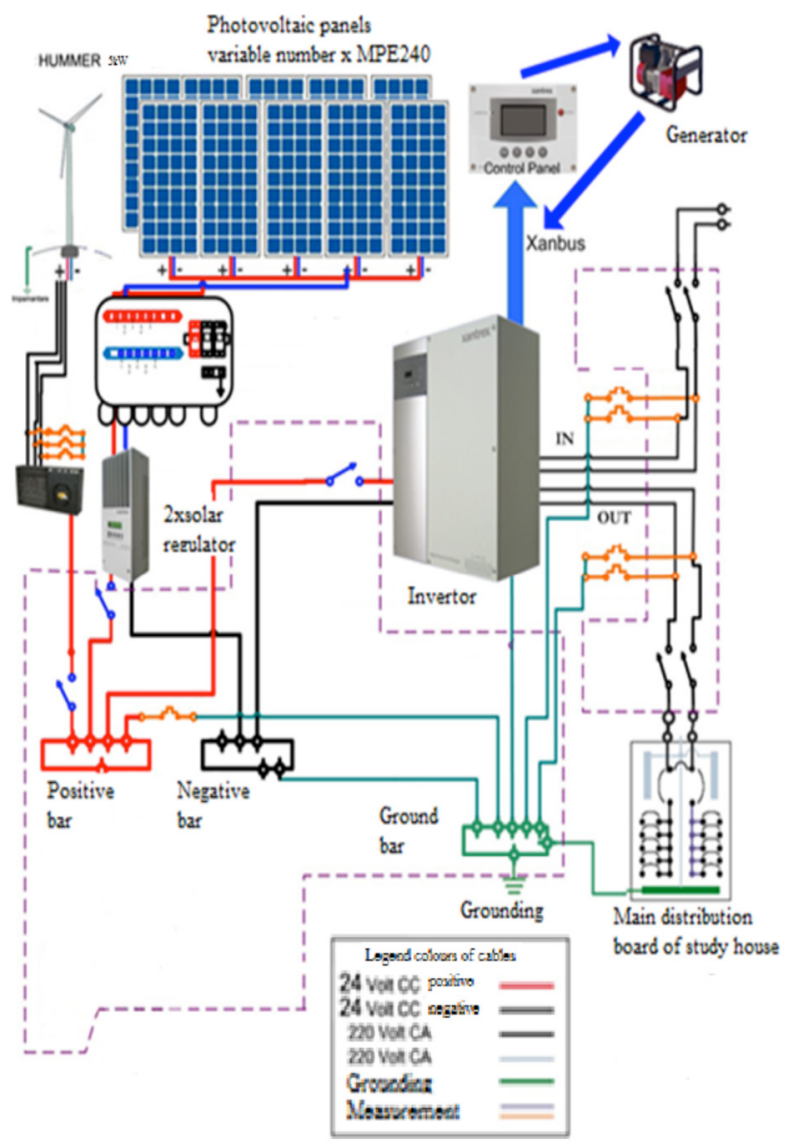

a)

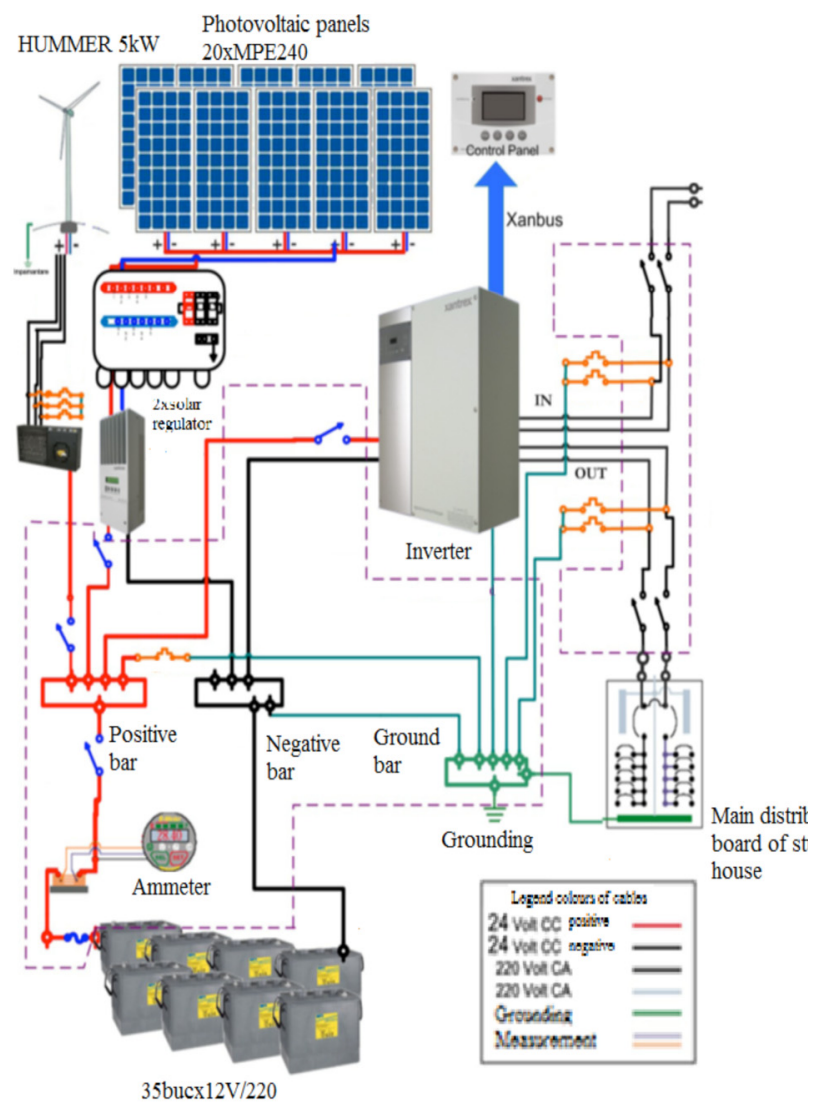

b)

Fig. 3. Working options chosen: (a) solution one with generator, (b) solution two storage.

studied, has the main rooms arranged towards South, the photovoltaic panels will be positioned on the roof of living room, south oriented, to have an optimum operation. Roof's living has $35^{\circ}$, slope ideal for photovoltaic panels.

The building has resistance structure made of monolithic reinforced concrete frames arranged in two orthogonal directions enough to withstand the loads of the house and the weight added by photovoltaic panels and the structure.

For location chosen in this paper we present an option with two solutions. The first solution, where we have a turbine of the $5 \mathrm{~kW}, 20 \mathrm{PV}$ modules $240 \mathrm{Wp}$ each and a $32 \mathrm{kVA}$ power generator (Fig. 3). A second storage solution, which uses a turbine of $5 \mathrm{~kW}, 20$ photovoltaic panels $240 \mathrm{Wp}$ each and storage batteries 12 V 35 (230 Ah) (Fig. 3b).

Connection to the national electricity network is available to all households and if it desired it can be connected to this hybrid renewable energy system.

\section{Results and discussion}

Calculation of energy was conducted from two assumptions: first hypothesis - seasonal situation unfavorable in winter and summer when energy consumption is maximum and favorable situation in spring or fall season when is the average energy consumption (Fig. 4). For home study were calculated: energy requirements, $P n$, energy production obtained from hybrid plants, $P p$, the energy difference between appropriate and manufacturing, and surplus power, Ex. Thus, the solution 1 and 2 of the calculations, indicates that the average value of energy demand is $1500 \mathrm{kWh} /$ year. Energy production for both solutions the value is $1400 \mathrm{kWh} /$ year. Instead, the difference between the need of energy and the production of energy of solution 1 is negative, but for solution 2 is positive values, the average is around $500 \mathrm{kWh} /$ year, hence the second solution storage hybrid system is more reliable choice. For extra power, the medium value is positioned less than $100 \mathrm{kWh} /$ year.

For the entire community were chosen five types of housing, based on a home study (type I) that shows all the facilities and the supply is made only with electricity from a hybrid plant. The remaining households have $50 \%$ of the consumption of the household type I (type II), $25 \%$ of the consumption type I (type III), $15 \%$ of the consumption type (type IV) and $5 \%$ of the consumption type (type V). Type I represent $31.92 \%$ of all households in the community chosen, type II represents $25.94 \%$, type III is $17.98 \%$, type IV is $14.74 \%$ and type $\mathrm{V}$ is $9.42 \%$.

Given the two types of storage solutions chosen and generator, maximum and average consumption was calculated for each type of household (Fig. 5). 


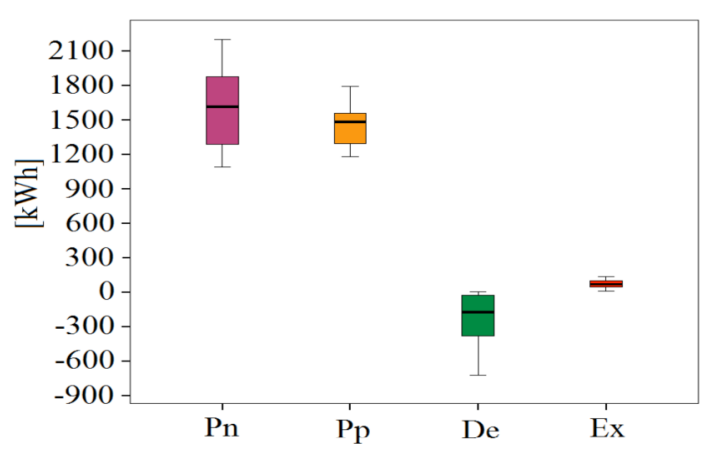

a)

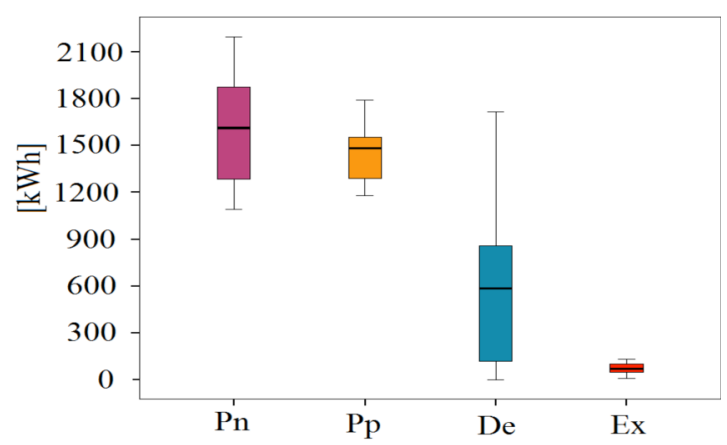

b)

Fig. 4. Maximum consumption for location chosen: (a) solution 1, (b) solution 2.

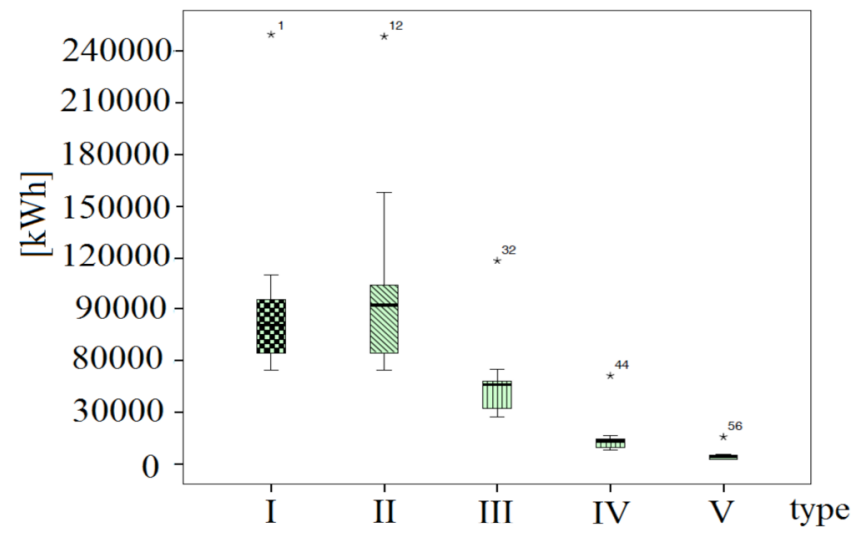

Fig. 5. Energy consumption by type of household.

For each type of house, the annual energy consumption was determined. It was made from the house of study, using percentages mentioned above. For type I, the average annual consumption is about 85,000 [kWh/year], while for housing about $10,000[\mathrm{kWh} /$ year] type $\mathrm{V}$, which is an appreciable difference between the two types of housing.

In terms of payback, the study with storage is a solution with a faster recovery because it is the solution that, over the years should not use the financial funds other than storage replacement. In comparison, first solution, with the generator, is using financial funds when purchasing hybrid plants, but also over the years to cover the difference of energy between the energy demand and production.

\section{Conclusions}

Of the two solutions, the storage solution is the most reliable in terms of cost. If in the months when the plant does not provide enough energy for home studied, implicitly community, the hybrid installation must function, which means costs for every household in hand. For this solution, the only months in which the beneficiary home studied must not pay for electricity are May, June, July, August, and September. In comparison, in the second solution with storage, the beneficiary home studied must not pay for the energy consumed. Using a hybrid power system offers a number of advantages: it substantially reduces emissions of carbon dioxide and other air pollutants; create new ways of local development and economic and social cohesion brings new business opportunities and create new jobs; reduce dependence on imports of conventional fuels, it increases the reliability of energy supply. Hence the need to support adequate local capacity to ensure that these technologies can be used and maintained by local staff. Energy will become a major in land cover [13]. This study can be extended to different situations with other working input data, once the hybrid plant is selected that uses solar and wind energy.

This work was performed as a part of research supported by the UEFISCDI PN2 - PCCA, project ECOMAGIS no. 69/2012 and project COSMOMAR no. 58/2013 financed by STAR Program of ROSA.

\section{References}

1. Renewable Energy Policy Network for the 21st Century REN21 (2015)

2. IPCC Climate Change, 2014 Impacts, Adaptation, and Vulnerability, Working Group II, Contribution to the Fifth Assessment Report of the Intergovernmental Panel on Climate Change (2014)

3. R. Pravalie, G. Bandoc, Aridity variability in the last five decades in the Dobrogea Region, Romania, Arid Land Res. Manage. 29, 1 (2015)

4. G. Bandoc, Costal phenologic cycles for Sfântu Gheorghe station (the Danube Delta), J. Environ. Prot. Ecol. 9, 953 (2009)

5. G. Bandoc, R. Pravalie, Climatic water balance dynamics over the last five decades in Romania's most arid region, Dobrogea, J. Geogr. Sci. 25, 1307 (2015). DOI:10.1007/ s11442-015-1236-1

6. G. Bridge, S. Bouzarovski, M. Bradshaw, N. Nick Eyre, Geographies of energy transition: space, place and the lowcarbon economy, Energy Policy 53, 331 (2013)

7. R. Araneo, S. Celozzi, Eco-sustainable routing of power lines for the connection of renewable energy plants to the Italian high-voltage grid Chiara Vergine, Int. J. Energy Environ. Eng. 6, 9 (2015) 
8. A. Chauhan, R.P. Saini, A review on Integrated Renewable Energy System based power generation for stand-alone applications: configurations, storage options, sizing methodologies and control, Renew. Sustain. Energy Rev. 38, 99 (2014)

9. D. Neves, C.A. Silva, S. Connors, Design and implementation of hybrid renewable energy systems on micro-communities: a review on case studies, Renew. Sustain. Energy Rev. 31, 935 (2014)

10. G. Bandoc, M. Degeratu, A.M.S. Florescu, E. Dragomir, Variance analysis of wind characteristics for energy conversion, J. Environ. Prot. Ecol. 14, 1760 (2013)
11. A.M.S. Florescu, G. Bandoc, M. Degeratu, Analysis of environmental characteristics and operational reports of small and medium turbines, Appl. Mech. Mater. 178-181, $973(2012)$

12. A.M.S. Florescu, G. Bandoc, M. Degeratu, Energy efficiency evaluation of wind energy based on energy reports, Adv. Mater. Res. 1008-1009, 188 (2014)

13. C.A. Miller, J. Richter, J. O'Leary, Socio-energy systems design: a policy framework for energy transitions, Energy Res. Soc. Sci. 6, 29 (2015)

Cite this article as: Georgeta Bandoc, Ana-Maria Smaranda Florescu, Mircea Degeratu, Remus Pravalie, Use of hybrid renewable energy systems for small communities, Renew. Energy Environ. Sustain. 1, 29 (2016) 